\title{
Forecasting Volatility of USD/MUR Exchange Rate using a GARCH $(1,1)$ model with GED and Student's-t errors
}

\author{
D Ng Cheong Vee* \\ Faculty of Science, \\ University of Mauritius, \\ Réduit \\ Email: dany_priest@servihoo.com
}

P Nunkoo Gonpot

Faculty of Science,

University of Mauritius,

Réduit

Email:pgonpot@uom.ac.mu

N Sookia

Faculty of Science,

University of Mauritius,

Réduit

Email:sookian@uom.ac.mu

Paper Accepted on 06 January 2011

\begin{abstract}
This paper aims at evaluating volatility forecasts for the US Dollar/Mauritian Rupee exchange rate obtained via a GARCH $(1,1)$ model under two distributional assumptions: the Generalized Error Distribution (GED) and the Student's-t distribution. We make use of daily data to evaluate the parameters of each model and produce volatility estimates. The forecasting ability is subsequently assessed using the symmetric loss functions which are the Mean Absolute Error(MAE) and Root Mean Square Error (RMSE). The latter show that both distributions may forecast quite well with a slight advantage to the GARCH(1,1)- GED for out-of-sample forecasts.

Key words and phrases: Volatility, GARCH, Student-t, GED, MAE, RMSE.

*For correspondences and reprints
\end{abstract}




\section{INTRODUCTION}

The need for accurate forecasting of volatility in financial markets is critical with regard to "investment, financial risk management and monetary policy making" (Poon \& Granger (2003)). Christoffersen \& Diebold (1998) also point out the relevance of volatility forecastability in risk management on the short term. The Mauritian economy is very sensible to fluctuations in the USD/MUR exchange rate given the fact that we generally import in US dollars. Moreover, banks as well as other financial institutions usually invest in foreign exchange instruments thus the need for accurate modelling and forecasting of volatility. This study is in fact the first which aims at fitting a volatility model to the US dollar - Mauritian Rupee Exchange rate and thereafter assessing the accuracy of the forecasts produced.

Financial time series tend to exhibit certain characteristic features such as volatility clustering and are usually leptokurtic . The Generalised AutoRegressive Conditional Heteroscedasticity (GARCH) model of Bollerslev (1986) has gained in popularity because of its ability to address these issues. Hansen \& Lunde (2005) argue that no reasonable evidence can be found that would allow to conclude to the inferiority of the $\operatorname{GARCH}(1,1)$ as compared to more complicated models. In fact the $\operatorname{GARCH}(1,1)$ model outperforms other models considered, non including asymmetric models, in estimating volatility of foreign exchange rate. Recently, Hung-Chung et al. (2009) have shown that a GARCH model with an underlying leptokurtic asymmetric distribution outperforms one with an underlying Normal distribution, for modelling volatility of the Chinese Stock Market. Similar studies by Wilhelmsson (2006) have demonstrated that 
the use of fat tailed error distributions within a $\operatorname{GARCH}(1,1)$ framework leads to improved volatility forecasts. The former uses nine possible error distributions to model the volatility of the Standard \& Poor's 500 with the leptokurtic distributions working out best. The author uses the Mean Absolute Error and Heteroscedasticity-adjusted MAE to evaluate the forecasts. Chuanga et al. (2007) also finds that a student's t distribution as distributional assumption to a GARCH model produces better forecasts as compared to the Exponential distribution and a mixture of Normal distributions. An extension of the GARCH model, the GARCH in Mean is used by Ryan \& Worthington (2004) to assess the impact of market, interest rate and foreign exchange rate risks on the sensitivity of Australian bank Stock Returns. Olowe (2009) investigates the volatility of Nigerian Naira / Dollar Exchange rate by fitting six univariate GARCH models using monthly data and concludes that the best performing models are the Asymmetric Power ARCH and TS - GARCH. The models used in this study use Student's t innovations. In Ghana, Adjasi (2008) examines the impact of Exchange rate volatility on the local Stock Exchange. The authors make use of an Exponential GARCH for their purpose and observe the negative relationship between the exchange rate volatility and stock market returns. Balaban (2004) compares the forecast - ability of symmetric and asymmetric GARCH models. The US Dollar / Deutsche Mark returns series is filtered using an $\mathrm{AR}(1)$ process and the $\operatorname{GARCH}(1,1)$, GJR-GARCH(1,1) and $\operatorname{EGARCH}(1,1)$ volatility equations are used. The author concludes that the EGARCH performs better in producing out of sample forecasts with the $\operatorname{GARCH}(1,1)$ closely following whereas the GJR-GARCH fares worst. The list of work on the forecast ability of asymmetric GARCH models include 
the research by Awartani \& Corradi (2005) where the authors compare the performance of the classical $\operatorname{GARCH}(1,1)$ versus other asymmetric variations using the out sample. The asymmetric models are found to produce better forecasts. However, the $\operatorname{GARCH}(1,1)$ is seen to outperform other GARCH models not taking into consideration the asymmetry property. Wang \& Yang (2009) consider asymmetric GARCH models for measuring the volatility for the AUD/USD, GBP/USD and JPY/USD exchange rates.

Here we focus on the USD/MUR exchange rate using the Student's-t and Generalized Error as underlying distributions for the innovations of the variance equation and compare the forecasting ability of the models, both in-sample and out-of-sample using the Mean Absolute Error and Root Mean Square Error as metrics.

\section{DATA AND EMPIRICAL PROPERTIES}

The daily exchange rates of the US Dollar against the Mauritian Rupee for the period 30 June 2003 to 31 March 2008 are used. These make a total of 1737 observations of the spot price and are converted for the needs of fitting the model to a logarithmic returns series. If the price series is denoted $\left\{X_{t}\right\}$, then the $\log$ returns series $r_{t}$ is such that,

$$
r_{t}=\ln \left(\frac{X_{t}}{X_{t-1}}\right) .
$$

Figure 1 illustrates the time series of prices and logarithmic returns. The plot of the returns series shows that heteroscedasticity is present. In fact, we observe that periods of high volatility as well as those of lower volatility occur 
in clusters.

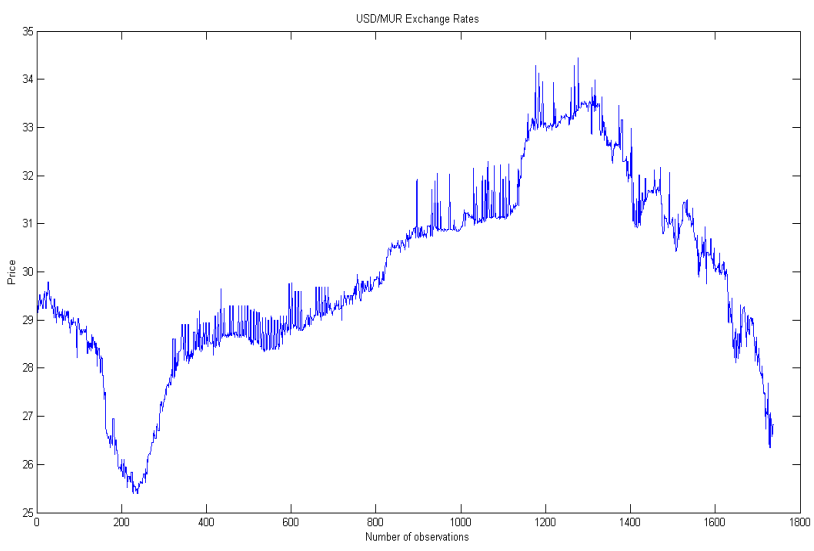

(a) Prices

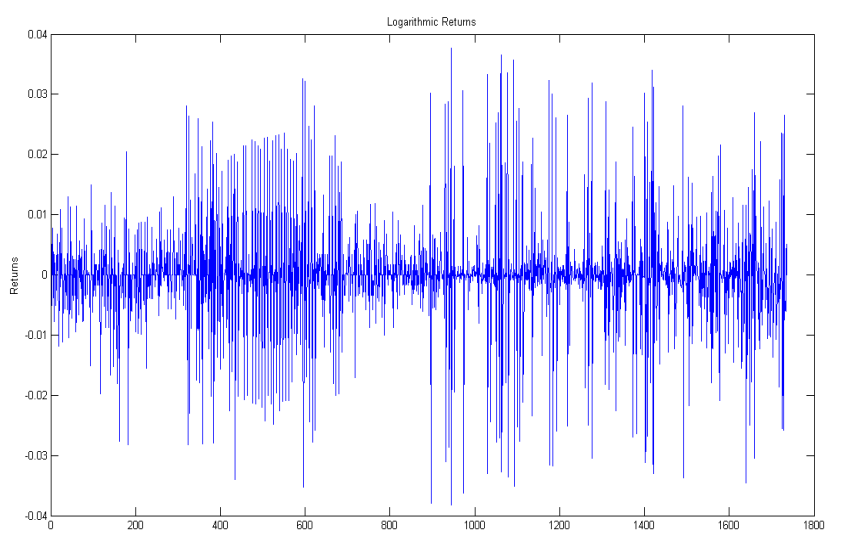

(b) Log Returns

Figure 1: Prices and corresponding Logarithmic Returns for the period $30 / 06 / 03$ to $31 / 03 / 08$

From table 1, it may be seen that the mean is close to zero. We also note that the returns exhibit negative skewness and excess kurtosis. The Jarque Bera test performed at 5 percent significance rejects the null hypothesis of zero skewness and zero excess kurtosis $\left(\chi_{\text {test }}^{2}=512.0418>5.99\right)$. This confirms 
Table 1: Descriptive Statistics for the USD-MRU Daily Exchange Rate

\begin{tabular}{cc}
\hline Mean & $6.24284 \mathrm{E}-05$ \\
Median & 0 \\
Standard Deviation & 0.009096707 \\
Range & 0.075940364 \\
Skewness & -0.146618179 \\
Kurtosis & 7.442496209 \\
\hline Jarque-Bera & 512.0418 \\
LBP & 153.2464 \\
ARCH-test & 80.0652 \\
\hline
\end{tabular}

departure from normality. The Ljung-Box-Pierce test at $5 \%$ significance level and with up to 5 lags allows us to deduce the lack of randomness in the data, that is, presence of autocorrelation. The critical value for the test is 11.0705. Similarly Engle's ARCH test at 5 percent significance with up to five lags also rejects the null hypothesis that the returns form a random sequence of Normal disturbances hence presence of heteroscedasticity (Critical value $=11.0705$ ). These features suggest the use of a GARCH model for capturing the time varying volatility.

\section{VOLATILITY MODEL}

For the purpose of this paper we make use of a GARCH $(1,1)$ model for conditional variance and a MA(1)(Moving Average) model for the mean equation. The GARCH $(1,1)$ model is relatively easy to estimate given the few parameters to be estimated and is seen to perform quite well (see Hansen \& Lunde (2005)). The MA(1) model is used as a filter for the returns series. Thus from the returns series, we are able to extract independent and identically 
distributed innovations $\left\{\varepsilon_{t}\right\}$. We shall use the following

$$
\begin{aligned}
& r_{t}=C+\varepsilon_{t}+\theta \varepsilon_{t-1} \\
& \varepsilon_{t}=z_{t} \sigma_{t} \\
& \sigma_{t}^{2}=\omega+\alpha \varepsilon_{t-1}^{2}+\beta \sigma_{t-1}^{2} .
\end{aligned}
$$

where $\varepsilon_{t}$ is the innovation, $\sigma_{t}$, the volatility and $z_{t}$ is an i.i.d variable such that $z_{t} \sim D$, where $D$ is some distribution with mean zero. In our case $D$ will be the Student's-t distribution or the GED with the following probability density functions:

\section{Student's t}

$$
f(t)=\frac{\nu^{\nu / 2} \Gamma\left(\frac{\nu+1}{2}\right)}{\sqrt{\pi} \Gamma(\nu / 2) \sqrt{\frac{(\nu-2) \sigma_{t}^{2}}{\nu}}}\left(\nu+\frac{\nu t^{2}}{(\nu-2) \sigma_{t}^{2}}\right)^{-(\nu+1) / 2}
$$

\section{Generalised Error Distribution}

$$
f(t)=\nu \exp \left(-\frac{1}{2}\left|\frac{t}{\lambda \sigma_{t}}\right|\right)\left[2^{\frac{\nu+1}{\nu}} \Gamma\left(\frac{1}{\nu}\right) \lambda \sigma_{t}\right]^{-1}
$$

where $\lambda=\left[\frac{\Gamma(1 / \nu}{2^{(2 / \nu)} \Gamma(3 / \nu)}\right]^{0.5} \cdot \nu$ is a shape parameter to be estimated during Maximum Likelihood Estimation. These distributions are more peaked and have fatter tails than the Normal distribution. This corresponds better to the empirical properties of the returns data.

The parameters $\omega, \alpha$, and $\beta$ are non negative with $\alpha+\beta<1$ to ensure stationarity.

The parameters of the model are estimated on MATLABß R2006a using 
Kevin Sheppard's UCSD_Garch Toolbox and J P Lesage's Econometric Toolbox. The set of 1736 returns is divided into two parts, an estimation sample comprising 1486 observations (for in-sample evaluation) and a window of 250 returns for out-of-sample evaluation. The parameters of the mean and variance equations are estimated for each distribution. The values of the parameters, robust $\mathrm{T}$ statistics and $\mathrm{p}$ - values are shown in Tables and. From the p-values obtained, we may deduce that the parameters for both models are significant at the $5 \%$ level.

Table 2: Parameter Estimates of the GARCH $(1,1)$ - GED equation

\begin{tabular}{cccc}
\hline & & Robust T Statiscics & $\mathrm{p}-$ value \\
\hline$\omega$ & $4.63 \mathrm{E}-03$ & 5.1086 & $3.66 \mathrm{E}-07$ \\
$\alpha$ & 0.282179 & 6.0685 & $1.64 \mathrm{E}-09$ \\
$\beta$ & 0.674167 & 18.2067 & 0 \\
$\nu$ & 1.1 & 20.6956 & 0
\end{tabular}

Table 3: Parameter Estimates of the GARCH $(1,1)$ - t equation

\begin{tabular}{cccc}
\hline & & Robust T Statiscics & $\mathrm{p}-$ value \\
\hline$\omega$ & $6.08 \mathrm{E}-06$ & 2.0023 & 0.0454 \\
$\alpha$ & 0.517763 & 5.3606 & $9.61 \mathrm{E}-08$ \\
$\beta$ & 0.482235 & 2.2138 & 0.027 \\
$\nu$ & 3.3 & 1.1 & 0
\end{tabular}

We produce 250 'future' observations using the recurrence relations (2), (3) and (4) above. This constitutes the out-of-sample volatility forecasts shown in Figure 2. 


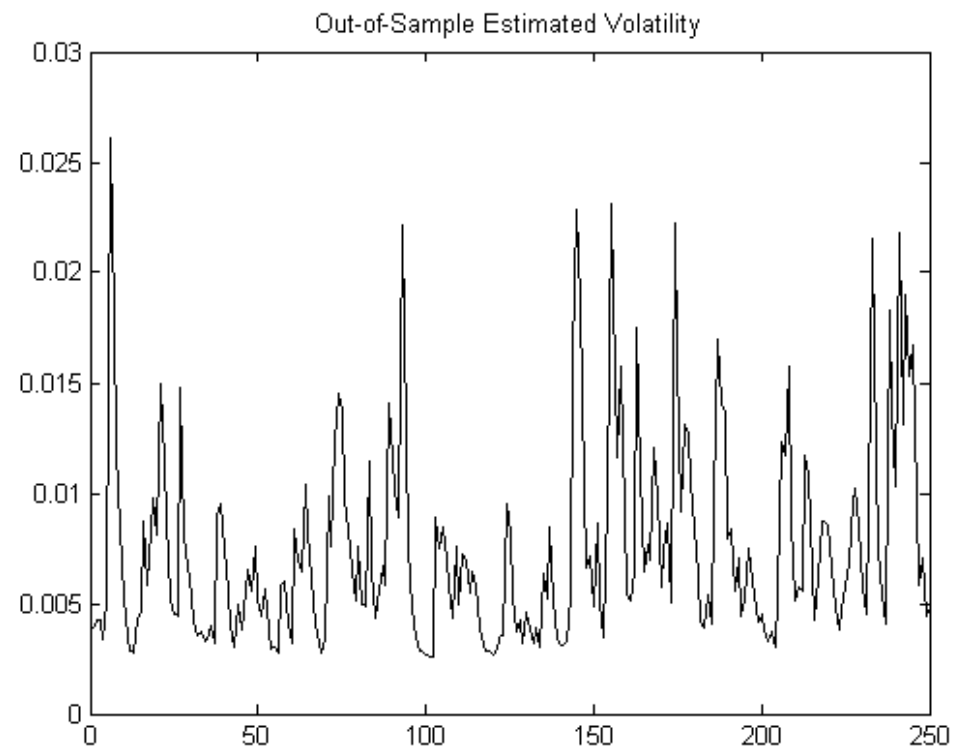

(a) $\operatorname{GARCH}(1,1)$-GED

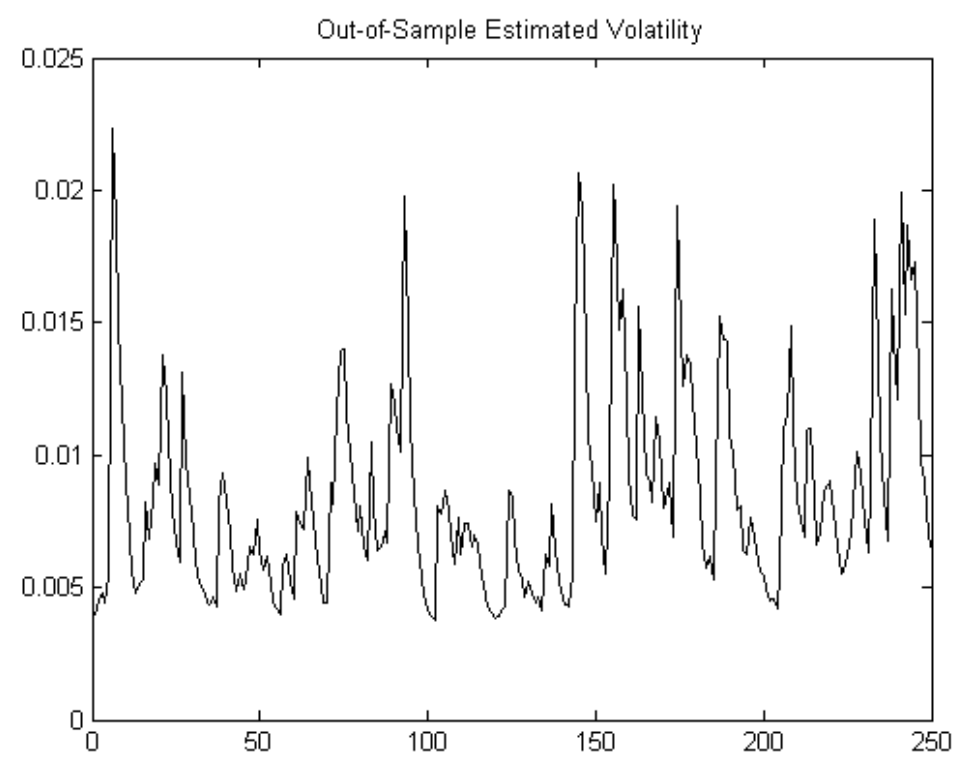

(b) GARCH(1,1)- Student's t

Figure 2: Out - Sample Volatility Forecasts under the 2 schemes 


\section{FORECAST EVALUATION}

We make use of 2 metrics for forecast evaluation both in and out of sample. We consider the Mean Absolute Error (MAE) and the Root Mean Square Error (RMSE) defined as follows:

$$
\begin{aligned}
& M A E=\frac{1}{n} \sum_{t=1}^{n}\left|r_{t}^{2}-\sigma_{t}^{2}\right| \\
& R M S E=\sqrt{\frac{1}{n} \sum_{t=1}^{n}\left(r_{t}^{2}-\sigma_{t}^{2}\right)^{2}}
\end{aligned}
$$

where $r_{t}^{2}$ is used as a substitute for the realized or actual variance (see HungChung et al. (2009) and Franses \& Dijk (1996) who employ the same proxy for realized volatility) and $\sigma_{t}^{2}$ is the forecasted variance. These two symmetric statistical loss functions are among the most popular methods for evaluating the forecasting power of a model given their simple mathematical forms. The RMSE assigns greater weight to large forecast errors. This fact is dealt with using the MAE which on the contrary assigns equal weights to both over and under predictions of volatility. Table 4 shows the mean absolute errors and root mean square errors for the forecasted volatility. We observe that the two models seem to produce relatively accurate forecasts given the quite low MAE and RMSE values. The lower MAE and RMSE scores produced by the GARCH-GED indicate that the latter performs slightly better that the GARCH with t errors. Figure 3 shows the actual returns versus the forecasted volatility within the evaluation sample. 


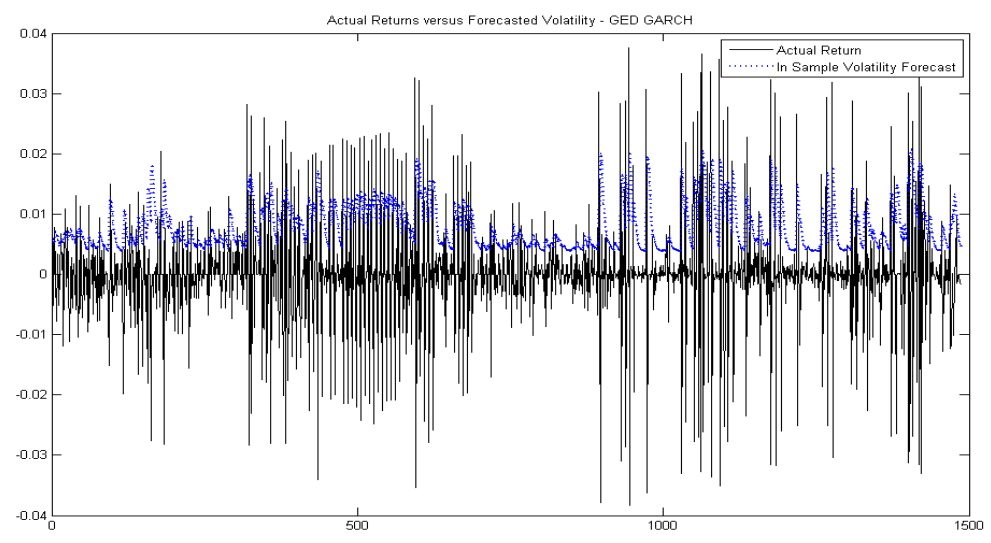

(a) $\operatorname{GARCH}(1,1)-$ GED

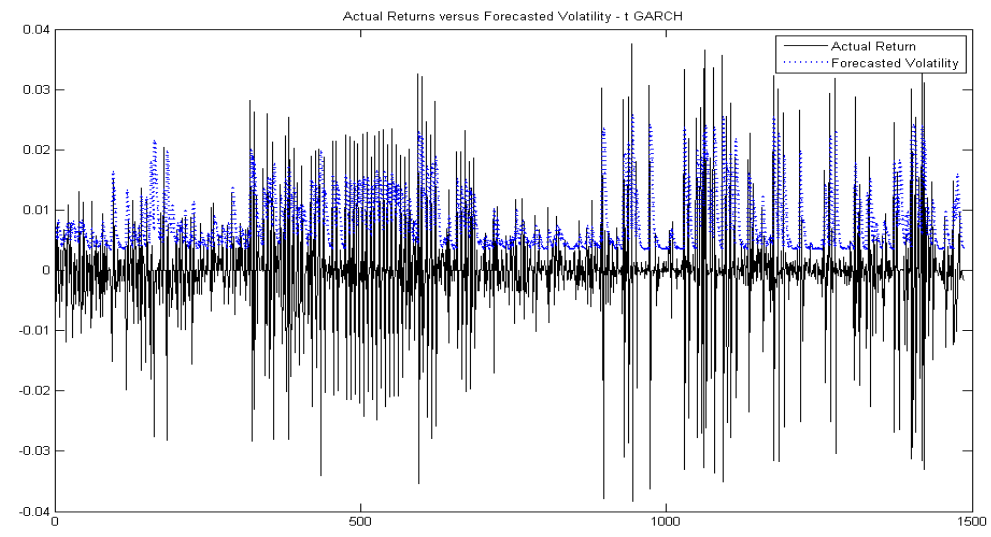

(b) GARCH(1,1)- Student's t

Figure 3: Forecasted Volatility versus Actual Returns - In Sample

\section{CONCLUSIONS}

The accurate measurement and forecasting of the volatility of financial markets is crucial for the Mauritian economy. Firstly, Mauritius depends significantly on imports, secondly there is increasing amount of foreign investment and finally, important reserves are held in foreign exchange, especially US dollars. These make the study of fluctuations in foreign exchange rates a key issue. 
Table 4: Mean Absolute Error and Root Mean Square Error Values

\begin{tabular}{ccc}
\hline & $\begin{array}{c}\text { MAE } \\
\times 10^{-3}\end{array}$ & $\begin{array}{c}\text { RMSE } \\
\times 10^{-3}\end{array}$ \\
\hline Student's- t & & \\
& & \\
In-Sample & 0.1104 & 0.2027 \\
Out-of-Sample & 8.4523 & 9.2894 \\
\hline GED & & \\
& & \\
In-Sample & 0.1105 & 0.2033 \\
Out-of-Sample & 7.4601 & 8.6998
\end{tabular}

We have applied here the GARCH $(1,1)$ model with two underlying fat-tailed distributions for the errors namely, the Student's t and Generalized Error Distributions. Results obtained show that both models perform well with a slight advantage to the model with GED errors for forecasting out-of-sample volatility. The aspect of skewness was however not addressed in this paper. This characteristic is being tackled in a future paper by considering the skewed Student's-t (see Peters (2001)) or Skewed GED distributions(see Hung-Chung et al. (2009)).

\section{ACKNOWLEDGEMENTS}

The first author wishes to thank the Tertiary Education Commission and the University of Mauritius. 


\section{References}

Adjasi, C., H. S. A. D. (2008), 'Effect of exchange rate volatility on the ghana stock exchange', African Journal of Accounting, Economics, Finance and Banking Research. 3, 28-47.

Awartani, B. M. \& Corradi, V. (2005), 'Predicting the volatility of the S\&P500 stock index via GARCH models: the role of asymmetries', International Journal of Forecasting 21, 167-183.

Balaban, E. (2004), Forecasting exchange rate volatility., Working paper.

URL: http://ssrn.com/abstract $=494482$

Bollerslev, T. (1986), 'Generalized Autoregressive Conditional Heteroskedasticity', Journal of Econometrics 36, 394-419.

Christoffersen, P. F. \& Diebold, F. X. (1998), How relevant is volatility forecasting for financial risk management?, NBER Working Papers 6844, National Bureau of Economic Research, Inc.

URL: http://ideas.repec.org/p/nbr/nberwo/6844.html

Chuanga, I.-Y., Lub, J.-R. \& Leea, P.-H. (2007), 'Forecasting volatility in the financial markets: a comparison of alternative distributional assumptions', Applied Financial Economics 17, 1051-1060.

Franses, P. H. \& Dijk, D. V. (1996), 'Forecasting Stock Market Volatility Using(non-linear) Garch Models', Journal of Forecasting 15, 229-235.

Hansen, P. R. \& Lunde, A. (2005), 'A forecast comparison of volatility mod- 
els: does anything beat a $\operatorname{GARCH}(1,1)$ ?', Journal of Applied Econometrics 20, 873889 .

Hung-Chung, L., Yen-Hsien, L. \& Ming-Chih, L. (2009), 'Forecasting China Stock Markets Volatility via GARCH Models Under Skewed-GED Distribution.', Journal of Money, Investment and Banking pp. 542-547.

Olowe, R. (2009), 'Modelling naira/dollar exchange rate volatility: Application of garch and assymetric models.', International Review of Business Research Papers 5, 377-398.

Peters, J. (2001), Estimating and forecasting volatility of stock indices using asymmetric GARCH models and (skewed) Student-t densities, Working paper, EAA Business School, University of Liege.

Poon, S. \& Granger, C. (2003), 'Forecasting Volatility in Financial Markets: A Review', Journal of Economic Literature 41, 478-539.

Ryan, S. K. \& Worthington, A. C. (2004), 'Market, interest rate and foreign exchange rate risk in Australian banking: A GARCH-M approach', International Journal of Applied Business and Economic Research 2, 81-103.

Wang, J. \& Yang, M. (2009), 'Asymmetric volatility in the foreign exchange markets', Journal of International Financial Markets, Institutions and Money 19, 597-615.

Wilhelmsson, A. (2006), 'Garch forecasting performance under different distribution assumptions', Journal of Forecasting 25, 561-578. 